\title{
Use of Large Scale Assessment Finding in South Asia: An Experience of Nepal
}

\author{
Prof. Dr. Chandra Mani Paudel \\ Chairperson
}

National Examinations Board, Nepal
Dr. Ram Chandra Panday

Director

Research, Quality \& Governance Reform

National Examinations Board, Nepal

\begin{abstract}
This paper tries to present results from a systematic review of literature that reviewed the large-scale assessments finding in the South Asian context especially focusing Nepal. The main objective of the LEAP programme is to reform the quality of learning in the Asia-Pacific region by developing capacity of the Member States to collect, analyze and utilize international and national assessment data identifying learning enablers. The review has identified the high order skills overshadowed by rote learning. It has also employed Item Response Theory (IRT) making assessments comparable and connected with the previous levels. International Assessments such as the Programme for International Student Assessment (PISA) and the Trends in Mathematics and Science Study (TIMSS) collected vast amounts of data on schools, students and households. The use of education-related "big data" for evidence-based policy making is limited, partly due to insufficient institutional capacity of countries to analyze such data and link results with policies.
\end{abstract}

Keywords: Assessment, Grading, Equivalence, Mapping, etc.

\section{Introduction}

National Examinations Board (NEB), Nepal is an autonomous independent body which was established on $29^{\text {th }}$ June 2016 by the Education Act $8^{\text {th }}$ amendment - 1971 for the secondary level examinations in the country by combining Office of the Controller of Examinations and Higher Secondary Education Board. This Board has the sole authority, standing and competence to manage and deliver quality public examinations from Grades IX to XII. It manages and conducts all secondary level examinations with greater efficiency (Panday, 2017).

The $8^{\text {th }}$ amendment education Act- 1971, envisions classes 1 to 8 as the Basic Education, with classes 9 to 12 comprising the Secondary Education. The then Higher Secondary Education Board (HSEB) and the Office of the Controller of Examinations, which used to hold the examinations of Higher Secondary Level Certificate and School 
Leaving Certificate (SLC) were dissolved merged under National Examinations Board (NEB). The courses of Grade XI has been started to evaluate on the basis of grading system whereas the courses of Grade XII are to be evaluated from this year's examinations held on 23 April 2018.

Basic Education introduced Continuous Assessment System which has helped teachers make portfolios. Private and public schools have been practicing grade-wise early examinations. There are external examinations in Grades VIII at grade X, XI and XII.

\section{Grading system in school education}

It was the second time the letter grading evaluation system was practiced in Secondary Education Examination (SEE). Individual subjects have been graded under alphabetical letter grading ( $\mathrm{E}$ to $\mathrm{A}+$ ) while aggregation has been graded in numerical GPA ranging from 0.8 to 4.0. No students is placed under the failed category in the SEE but those students who have obtained up to C or 2.0 GPA in their exams or in an individual subject can appear in the supplementary exams for upgrading their marks. The students who missed up to two subject examinations are allowed to appear in the supplementary exams. Since 2018, NEB has been implementing the Grading System.

\section{SEE-Result 2017}

A total of 462,136 students appeared in the SEE examinations in 2017. Out of total students registered for the exams, 445,564 were regular students whereas 16,572 exempted students. A total of 4,284 students in the regular category achieved results in the Grade Point Average (GPA) range of 3.65 to 4, whereas 42,427 students achieved results in the GPA ranging from 3.25 to 3.60. Likewise, A total of 50, 646 students achieved in the range of 2.85 to 3.02 , whereas a total of 61,955 students achieved in the range of 2.45 to 2.80 .A total of 91,314 students achieved in the range of 2.5 to 2.40 whereas 108,464 students achieved in the GPA range of 1.65 to 2.00. A total of 64, 577 students achieved results in the GPA range of 1.25 to 1.60. (SEE, 2017).Similarly, A total of 483,967 students including those from technical groups were registered to appear in the SEE but 11,825 were disqualified due to insufficient attendance while 10,006 were absent in the exams in the same year 2017.

\section{NEB Result (Grade XI) - 2016}

A total of 2, 66,094 students appeared in the Grade XI examinations in 2016. Out of total students enrolled in the Grade XI, 2, 39,933 students appeared in the Grade XII examination in 2017. The result of Grade XII categories are as follows: 
Table 1. National educations board result-2016 grade xi

\begin{tabular}{lcc}
\hline \multicolumn{1}{c}{ Result } & Students & Percent \\
Distinction & 9,810 & 4.08 \\
First Division & 38,673 & 16.12 \\
2nd Division & 60,438 & 25.19 \\
3rd Division & 8,846 & 3.69 \\
Failed & $1,22,166$ & 50.92 \\
Total no of students & $2,39,933$ & $100 \%$ \\
\hline
\end{tabular}

This result shows that more than half (50.92) percent students were failed in grade XI examination under numerical system. A very less (4.08) percent students have secured distinction whereas $16.12,25.19$ and 3.69 percent students have achieved first, second and third division respectively.

\section{NEB Result-2018 under grading system}

The result of Grade XI published in the grading system in 2018. It has been graded under the Subject wise Alphabetical Letter Grading from E to $\mathrm{A}^{+}$. A total of 3, 47,748 students appeared in the Grade XI examinations of 189 subjects in 2017. They obtained the following Letter Grades on the basis of out of $24,74,722$ subject answer sheets in 2018 .

Table 2. Grades in answers sheets

\begin{tabular}{cc}
\hline Grade & Answers sheets \\
A + & $3,04,166$ \\
A & $2,19,482$ \\
B + & $1,55,270$ \\
B & $2,19,231$ \\
C + & $3,13,788$ \\
C & $4,16,594$ \\
D + & $3,69,184$ \\
D & $2,11,331$ \\
E + & $1,83,731$ \\
Absent & 81,945 \\
Total answers sheet & $24,74,722$ \\
\hline
\end{tabular}




\section{Descriptions}

- One student may obtain different letter grades in different five subjects. So, there is no one to one relation between the number of students and letter grades.

- SEE evaluation is based on GPA whereas grade XI examination is based on subject wise letter grades.

- In April and May 2018, a total of 6, 99,991 students in Grade XI and 5, 48,833 students in Grade XII have appeared in the final examinations.

\section{Grading and equivalence}

After the implementation of Education Act, 2016, the previously known national level SLC examination of grade $\mathrm{X}$ has been renamed as secondary education examination (SEE), it is equivalent to GCSE, the academic qualification of the UK and Matriculation in India. If a student scores less than a GPA of 1.6 and fails to achieve a $\mathrm{D}^{+}$grade in at least one subject, he or she will be ineligible for promotion to grade XI whereas the eligibility of higher education for grade XII students depends on the criteria made by the higher education institutions. The current structure of courses in grade X, XI and XII are evaluated on the basis of GPA which ranges from 0to4. The scores are as mentioned below:

Table.3. Elaboration of letter grading

\begin{tabular}{ccl}
\hline Grade & GPA & \multicolumn{1}{c}{ Identical } \\
$\mathrm{A}+$ & 4 & Outstanding \\
$\mathrm{A}$ & 3.6 & Excellent \\
$\mathrm{B}+$ & 3.2 & Very good \\
$\mathrm{B}$ & 2.8 & Good \\
$\mathrm{C}+$ & 2.4 & Satisfactory \\
$\mathrm{C}$ & 2 & Acceptable \\
$\mathrm{D}+$ & 1.6 & Partially Acceptable \\
$\mathrm{D}$ & 1.2 & Insufficient \\
$\mathrm{E}$ & 0.8 & Very insufficient \\
\hline
\end{tabular}

\section{Objectives}

- To present results from a systematic review of literature that reviewed the largescale assessments finding in the South Asian context especially focusing Nepal.

- To identify the reform of LEAP programand the quality of learning in the AsiaPacific region by developing capacity of the Member States. 
- To collect, analyze and review international and national assessment data identifying learning enablers.

\section{Methods and materials}

This article is based on the secondary data which were collected from the documents related to education policies, practices and experiences of national and international trend of school education. By reviewing national and international documents and practices as well as organizing several meetings and discussions with ERO officials and the other relevant experts, the revised draft of the framework of each subject was presented to the respective subject committees that endorsed the framework document for NASA 2018 in Grade V.

\section{Role of Education for All and UNESCO}

After the establishment of Education for All (EFA) in 1990, there has been rapid growth in the number of countries participating in large-scale assessments of students' learning, particularly in low- and middle-income countries. EFA is a global movement led by UNESCO to coordinate development efforts across countries, institutions and other organizations to work towards meeting education goals for all children and youth (UNESCO, 2015).In order to improve the use of student learning assessment data in strengthening education systems, and to support evidence-based policy making in improving education quality, UNESCO's Asia-Pacific Regional Bureau for Education (UNESCO Bangkok) launched a regional programme called "Learning Enablers for Asia and the Pacific" (LEAP).The LEAP programme aims to develop capacity of the Member States in designing and implementing policies to improve learning based on evidence. For the implementation of the activities of LEAP, UNESCO Bangkok leverages the Network on Education Quality Monitoring in Asia-Pacific (NEQMAP). The main objective of the LEAP programme is to improve the quality of learning in the Asia-Pacific region by developing capacity of the Member States to collect, analyze and utilize international and national assessment data with an aim to identify learning enablers. This capacity will allow Member States to translate assessment results and evidence into policy formulation and implementation.

The LEAP programme activities have included a mapping study, regional capacity development workshops on utilizing assessment data, and a research study on analyzing national or international assessment data, involving 15 countries in the Asia-Pacific Region. In addition, a majority of countries have indicated their desire to participate in upcoming rounds of international assessments, such as PISA and TIMSS. 


\section{Continuous improvement of learning outcomes}

Countries of all income levels in the Asia-Pacific region are increasingly likely to have participated in a large-scale assessment of students' learning to ensure quality in education. Assessments are intended to provide information for evidence based policy and decision-making about education inputs and resourcing, with a view to the continuous improvement of learning outcomes. Concerns continue to be raised about the usefulness of international assessments for policymaking (Goldstein \&Thomas, 2008) and the use of national high-stakes assessments. Nevertheless, policy- and decision-makers are reinforcing the use of assessments to monitor progress towards education development goals for the 2030 education agenda and documenting country participation in assessment activities (UNESCO, 2015).

\section{Intended uses of assessments}

Large-scale assessments of students' learning are often used for multiple purposes, the assessment programs that are linked to education policy in the South Asia and are more frequently intended to ensure the quality of the education system. These assessments identify the strengths and weaknesses of the system over time through system monitoring. Japan used the Programme for International Student Assessment (PISA) and the Japanese national assessment program to develop an 'evidence-based improvement cycle' to monitor the quality of its education system over time (Wiseman, 2013).Montoya (2015) notes that stakeholders primarily use assessment data 'to assess and manage education systems' rather than using assessment data as 'a rich source of information to directly address the needs of students' Programme for International Student Assessment (PISA). International Assessments such as the Programme for International Student Assessment (PISA) and the Trends in Mathematics and Science Study (TIMSS) collect vast amounts of data on schools, students and households. However, the use of education-related "big data" for evidence-based policy making is limited, partly due to insufficient institutional capacity of countries to analyze such data and link results with policies. Many countries therefore rely on research findings from other countries and regions, even though these findings may not be relevant for their education systems.

\section{Polices of education system}

This review paper tries to identify the assessment of policy of education system. Assessments are most frequently used to inform and improve the development of assessment policies for the further monitoring and evaluation of the education system. The policy often establishes or modifies the conduct and use of assessments in the system and local levels. 
The standards also include expectations for higher proportions of students to report positive attitudes and interest towards learning, which was highlighted in recent PISA results (Break spear, 2012).The standards also include expectations for higher proportions of students to report positive attitudes and interest towards learning, which was highlighted in recent PISA results (Break spear, 2012).

\section{Influence of assessments in education policy}

Some evidence of large-scale assessments of students' learning being used in education policy was primarily found in literature about Australia, Japan, New Zealand, India, Indonesia and Singapore. Even though many low- and middle-income countries in the Asia-Pacific region are undertaking national assessments or participating in regional or international assessments, much less is known about the role assessments play in education policy. Education policy may be understood as policy change at one or numerous stages of a policy cycle. This review used a simplified model of a policy cycle (Sutcliffe \& Court, 2005).

\section{Inputs of India and Pakistan}

Annual Status of Education Report (ASER) Centre, an NGO affiliated with the Pratham Education Foundation (India) and Idara-e-Taleem-o-Agahi (ITA) (Pakistan), which conducts a large citizen-led assessment programme, participated from India and Pakistan and their inputs. It has mainly focused on the national, international or regional assessments. Pakistan was also represented by Ministry of Education officials. Lack of sufficient human resources, such as technical experts, for analyzing large-scale data is seen within many ministries of education in the region. This necessitates the hiring of such expertise from outside.

\section{An experience of Madhya Pradesh (India)}

In the Indian state of Madhya Pradesh, the Department of Education established a cell called state-wide Learn to Read initiative in 2005, in order to improve student literacy outcomes. Standardized student assessment results were used from 2006 to 2010 to support the implementation of the Learn to Read initiative. The data allowed the provision of teacher coaches and other supports to be effectively targeted to districts, schools and teachers. The education department also used standardized student assessment data to target additional remuneration for teachers (Mourshed, Chijoke, \& Barber, 2010). 


\section{An Experience of Pakistan}

Pakistan's citizen-led household assessment, the Annual Status of Education Report (ASER) Pakistan, has aligned its assessment goals and reporting with monitoring progress towards government-legislated development priorities, thereby increasing its use for government reporting and monitoring in education (ASER, 2014).

\section{Findings from the National Assessment (NASA)}

National Assessment of Student Achievement (NASA) was established under the Ministry of Education in 2010. The assessment of Grade VIII of 2011 results of three subjects viz Nepali, Mathematics and Social Studies came out 49\%, 43\% and 49\% respectively in 2013. It also showed the gaps between individual students, between urban and rural, private and public, Dalit (Backward cast) and Non-Dalit(Upward cast), Nepali speaking and other language groups. It also showed that girls and boys appeared close in learning achievements. The assessment of grades III and V of 2012 came out in 2014. The critical inputs were also received for change in teacher management. NASA has emphasized on measuring learning outcomes based on the combinations of knowledge, understanding and applications. The review has identified the high order skills overshadowed by rote learning. It has also employed Item Response Theory (IRT) making assessments comparable and connected with the previous levels. Ministry of Education, Nepal approved the following road map for National Assessment of Student Achievement (NASA) for grades III, V, and VII which was implemented successfully.

Table 4: Road-map of national assessment of student achievement (NASA)

\begin{tabular}{ccccccc}
\hline Grades & 2011 & 2012 & 2013 & 2014 & 2015 & 2016 \\
3 & & $\checkmark$ & & $\checkmark$ & & $\checkmark$ \\
5 & & $\checkmark$ & & $\checkmark$ & & $\checkmark$ \\
8 & $\checkmark$ & & $\checkmark$ & & $\checkmark$ & \\
\hline
\end{tabular}

The Education Act (8th amendment-1971) has provisioned the SLC exams to be held in grade XII as the School Leaving Certificate Examination (SLCE). It has also enshrined the provision of conducting exams in grade VII from districts, in grade X from region/ province and grade XII from the center under the umbrella of National Examinations Board, Nepal. Under the Ministry of Education, the framework for NASA- 2018 has been prepared by Education Review Office (ERO) to provide guidelines for the assessment of Grade V students' learning achievement in Mathematics and Nepali. The framework identifies and states the domains and constructs to be assessed. It specifies the assessment criteria and standards; describes item development process; 
explains sampling and methodological processes; outlines the structure of contextual questionnaires; and presents the data analysis process. ERO for the first time designed a NASA framework in 2016 for the national assessment of Grade VIII students. The document has been prepared by reviewing some international as well as national practices of NASA studies. Most of the aspects of assessment framework for Grade VIII, developed in 2016, have been adopted with a necessary revision and elaboration in the framework. Contemporary international practices such assessment framework for PISA, TIMSS, PIRLS and PCAP have been reviewed extensively and relevant practices have been adopted in the framework. Subject experts and teachers, and assessment experts have also contributed in developing the criteria and standards and in identifying the level of cognitive domain proposed in the frame work. The objective of the assessment framework is to obtain a reliable set of data of student learning measured through a scientifically-constructed standardized tests. However, considering that student learning achievement is influenced by a number of associated variables, NASA also collects relevant information through a set of questionnaires about the variables that are related with different aspects in students' learning achievement.

Reviewing various national and international practices, the study provides some significant areas and sources of information about the variables that are to be considered in such a large-scale national assessment. The review also suggests that there will be four major sources of information from which contextual information are collectedstudents, teachers, parents and head teachers. For NASA2018, (Grade V), questionnaires will be prepared for students, teachers and head teachers. The items related to parental support will be incorporated into student questionnaire. The information collected through these questionnaires will be related with students' test scores to explain how the contextual variables can influence students' learning achievement.

\section{The Ways Ahead / Future Plans}

This paper draws the following bullets towards developing an understanding not only of the ways in which large-scale assessments of students' learning are being used to inform and reform the education policy, but also of the factors that influence their use.

- Financing of assessment programs and agencies of the country are to be formally established under the NEB, Nepal.

- Information relevant to policy concerns should be ensured.

- Questions about factors related to student outcomes (e.g., students' socioeconomic background and availability of resources at school and at home) should be included. 
- Regular meetings and seminars between officials and policymakers should be organized in order to facilitate communication and understanding of results.

- The reporting of assessment results should include policy papers specifically targeted to policymakers, in accessible language and linking back to policy issues of the concerned authority.

- The technical soundness of the assessments is an important factor that has influenced the relationship between assessments and policymaking. To design and maintain the quality of assessments, highly developed technical skills are required at all stages of the assessment, from design and development, sampling, test administration and data collection, data cleaning and analysis, and reporting and dissemination of results. Likewise, capacity building of stakeholders who are engaged in assessments is necessary.

- Engagement in international or regional assessment programs should be considered the technical skills of assessment staff may be applied to national assessment programs.

- Capacity development programs for assessment agency human resources and policymakers, including through regional networks, technical assistance agencies, university courses or other training programs should be pursued.

- Assessments have a sound communication and dissemination strategy that engage all relevant stakeholders in this effort, including the media should be ensured in this regard.

\section{Conclusion}

In Nepal, the students of SLCE who score greater than D+ (1.6) can pursue higher education or apply in the Public Service Commission or different development agencies for the jobs whereas the students of technical subjects can also start their own business/jobs based on the courses they have studied. Per year investment on a child is 200 USD in Nepal whereas, it is 8000 USD in Organization for Economic Cooperation and Development (OECD) countries including, Norway. So, Nepal needs greater partnership for improving quality. Undoubtedly, more resources are needed for children's learning in Nepal and South Asian countries.

Moreover, external factors can have significant impact on the use of assessments for policy reform. The external issues may be related to political or economic instability, for example; stakeholders who are increasingly emphasizing on supporting education reform in conflict-affected and fragile countries should consider the ways that external factors impact the use of assessment to inform educational reform and evidence-based 
education policy which will foster the institutions like National Examinations Board, Nepal.

\section{References}

Annual Status of Education Report (ASER). (2014). Annual status of education report: ASERPakistan 2013 national. Lahore, Pakistan: South Asian Forum for Education Development (SAFED).

Benavot, A., \& Köseleci, N. (2015). Seeking quality in education: The growth of national learning assessments, (1990 -2013). Paper commissioned for the EFA Global Monitoring Report 2015, Education for All 2000-2015: Achievements and challenges. Paris: UNESCO.

Breakspear, S. (2012). The policy impact of PISA: An exploration of the normative effects of International benchmarking in school system performance. Paris: OECD.

Clarke, M. (2012). What matters most for student assessment systems: A framework paper?

Washington, DC: The World Bank.

Education Review Office. (2018). National assessment of student achievement, 2018. Sanothimi: ERO

Education Review Office. (2015). National assessment of student achievement, 2015. Grades 3 and 5. Sanothimi: ERO

Goldstein, H., \& Thomas, S.M. (2008). Reflections on the international comparative surveys debate. Assessment in Education: Principles, Policy \& Practice, 15(3), 215-222.

Mourshed, M., Chijioke, C., \& Barber, M. (2010). How the world's most improved school systems keep getting better. London: McKinsey and Company.

Panday, RC. (2017). Innovation in evaluation: Sahodaya. Delhi, India: Council of Boards of School Education (COBSE).

Sutcliffe S., \& Court, J. (2005). Evidence-based policymaking: What is it? How does it work? What relevance for developing countries? London: Overseas Development Institute.

Wiseman, A.W. (2013). Policy responses to PISA in comparative perspective. In H.D. Meyer \& A. Benavot (Eds.), PISA, power, and policy (pp. 303-322). Oxford: Symposium Books. 